\title{
On the structure Jacobi operator of a real hypersurface in complex projective space
}

\author{
Hyun Jin Lee · Juan de Dios Pérez • \\ Florentino G. Santos • Young Jin Suh
}

(C) Springer-Verlag 2008

\section{Erratum to: Monatsh Math DOI 10.1007/s00605-008-0025-7}

Unfortunately, an error occurred in the Acknowledgment section of this paper. The corrected Acknowledgment is given below.

Acknowledgments H. J. Lee is supported by KRF-2007-355-C00004, J. de D. Pérez is partially supported by MEC-FEDER Grant MTM2007-60731. The fourth author was supported by grant Proj. R17-2008-001-01001-0 from Korea Science \& Engineering Foundation.

The online version of the original article can be found under doi:10.1007/s00605-008-0025-7.

H. J. Lee · Y. J. Suh

Department of Mathematics, Kyungpook National University, Taegu 702-701, Republic of Korea e-mail: yjsuh@mail.knu.ac.kr

J. de Dios Pérez $(\varangle) \cdot$ F. G. Santos

Departamento de Geometria y Topologia, Universidad de Granada, 18071 Granada, Spain e-mail: jdperez@ugr.es

F. G. Santos

e-mail: florenti@ugr.es 